International Journal of Child, Youth and Family Studies (2013) 1: 42-53

\title{
EXPLORING THE LINK BETWEEN SCHOOL ATTENDANCE, DEVELOPMENTAL ASSETS, AND SOCIAL CAPITAL IN A FIRST NATIONS COMMUNITY
}

\section{Kim Sanderson, Bonnie Hutchinson, and Jana Grekul}

\begin{abstract}
In Alberta, concerns about the state of educational achievement among First Nations students have been widely reported. Academic literature has well established the link between poor school performance and delinquency. Miyo Wahkohtowin Community Education Authority of Ermineskin First Nation in Hobbema ("Miyo”) has identified one of its major concerns to be low attendance rates among many students. Based on the significant body of work related to risk and protective factors in school-aged children by the Search Institute of Minneapolis, and research related to social capital in Aboriginal communities by Mignone and O’Neil (2005) and others, this study draws on the standard Developmental Asset Profile developed by the Search Institute, and Mignone and O’Neil's (2005) standardized questions related to cultural and social capital in Aboriginal communities. Results from a survey administered to high school age students $(n=69)$ and attendance rates for the students, reveal a strong correlation between attendance rates and developmental asset scores. On the other hand, no correlation was revealed between attendance rates and sense of cultural heritage, or perceptions of a positive community context. Implications for building assets and social capital among youth, and strengthening community attachments are discussed.
\end{abstract}

Key Words: developmental assets, cultural capital, social capital, school attendance, First Nations

Acknowledgements: The authors would like to acknowledge the Centre for Criminal Justice Research at Mount Royal University in Calgary for funding this research and for their support and encouragement of independent Canadian research on criminal and social justice issues, and on safe communities.

Corresponding author: Kim Sanderson, M.A., Consultant, Full Circle Strategies, Inc., Box 20 Site 270, RR 2, Carvel, Alberta, Canada, TOE OHO. E-mail: kimsand@telus.net

Bonnie Hutchinson, M.A., Consultant, Hutchinson Associates. Telephone: (780) 429-3369. E-mail: bonniehutchinson@shaw.ca

Jana Grekul, Ph.D. is Assistant Professor of Sociology and Director of the B.A. (Criminology) program at the University of Alberta, Edmonton, Alberta, Canada, T6G 2R3.

E-mail: jana.grekul@ualberta.ca 
In Alberta, concerns regarding the state of education for First Nations students were highlighted in 2009-2010, when results from a northern school division inquiry (The Northland School Division Inquiry Team Report) revealed that in a jurisdiction where 95\% of students were First Nations or Métis: “...high school completion rates are low and ...few of these students complete four or more diploma examination subjects required to meet the entry requirements of most post-secondary institutions” (Government of Alberta, 2010, p. 22).

The link between poor academic performance and delinquency has been well established in academic literature. The results of a meta-analysis reported that students with: “...lower academic performance offended more frequently, committed more serious and violent offences and persisted in their offending” (Maguin \& Loeber, 1996, p. 145). An important factor that affects academic performance is regular attendance. Students who attend regularly are more likely to have success and to complete high school than students who attend less regularly.

Miyo Wahkohtowin Community Education Authority of Ermineskin First Nation in Hobbema, Alberta ("Miyo") is curious about the link between the engagement of First Nations students in their education, as measured by attendance rates, and their engagement with culture and community. In a Canadian study with black students in Toronto, for example, Solomon (1992) found that for black students, school resistance is a consequence of conflict between schools' cultural assumptions and rules and students' own cultural backgrounds and experiences. Might the same be true for First Nations students?

The Developmental Assets Profile survey and questions from Mignone and O’Neil's (2005) standardized social capital survey contain several items related to culture and cultural engagement. In developing this study, the researchers and Miyo representatives thought a comparison of the results between students who attend regularly and students who do not might reveal a link between school success, culture and community, as suggested by Solomon's study and the literature of social capital in Aboriginal communities. Results from these two research instruments create a potential for learning opportunities that can be shared with other First Nations communities.

\section{Aim of the study}

Miyo Wahkohtowin Community Education Authority operates the junior/senior high school and an alternative school on the Ermineskin reserve. They report that during the 20102011 school year approximately 39\% of high school students attended less than 75\% of school days. The student body is comprised of individuals from a fairly homogeneous community. Most of the students live in a rural environment and are bused to school. The majority of students are First Nations, and the vast majority of the students are from one of the four bands that make up the community of Hobbema. In spite of these similarities, some students attend regularly and achieve passing grades while others, from apparently similar circumstances, miss classes, achieve poor results, and eventually drop out.

Located about an hour south of the provincial capital city, Edmonton, the community of Hobbema is comprised of four Cree nations: Samson, Louis Bull, Montana, and Ermineskin. 
International Journal of Child, Youth and Family Studies (2013) 1: 42-53

Geographically the four groups are neighbours, but they operate independently of each other: Members of each band elect their own chiefs and councils, run schools, social agencies, and other forms of governance.

Hobbema shares characteristics that are common to many Aboriginal communities in Canada. These include a number of structurally-based disadvantages such as the long-term effects of colonialism, marginalization, government legislation, and the devastating residential schools policy employed in Canada from the 1840s until the 1980s (Brzozowski, Taylor-Butts, \& Johnson, 2006; Grekul \& LaBoucane-Benson 2008). As a result, Aboriginal communities struggle with issues relating to parenting, family dysfunction, substance abuse, and violence. Understandably these experiences have resulted in feelings of alienation, mistrust, and animosity toward mainstream institutions and authorities including teachers and the educational system, police and the courts (Mercredi, 2000; Trocme, Knoke, \& Blackstock, 2004; Grekul \& Sanderson, 2011).

It is against this backdrop that the current research project was conducted. Miyo Wahkohtowin Community Education Authority and the researchers agreed that the project should recognize the two distinct communities to which the students belonged - the school community itself and the broader cultural community. To situate possible solutions within these two communities, and to guide the study, the researchers looked to literature related to developmental assets of school-aged children and to recent Canadian research on social capital in Aboriginal communities.

The following research questions emerged from the discussion:

1. Do high school age students with a history of low school attendance have greater, lesser, or a similar number of developmental assets compared to students who attend school regularly?

2. Do high school age students with a history of low school attendance have greater, lesser, or a similar sense of their cultural identity, and perceptions of positive social capital in their community, compared to students who attend school regularly?

\section{Theoretical framework}

Since 1996, the Search Institute of Minneapolis, Minnesota has surveyed thousands of students throughout the United States. In analyzing the data, researchers identified 40 different factors ("developmental assets") that impacted the success of a child. These factors were divided into two categories. The 20 external assets included such things as family support, a caring school climate, and opportunities to be of service to others, while the 20 internal assets included factors such as honesty, cultural competence, and personal power. Miyo is interested in using the Developmental Asset Profile (DAP) to identify deficits and strengths in the acquisition of assets for high school age students at risk of failure and dropping out.

Another factor that impacts student motivation and ability to attend school regularly is the perception of safety, opportunities, and care ("social capital”) in their community. Social capital is the idea that communities work well or poorly based on the social dimensions of life. 
International Journal of Child, Youth and Family Studies (2013) 1: 42-53

For example, how life is lived in specific places depends on how people get along, whether they trust and respect each other, and the extent to which they share resources.

Mignone and O’Neil (2005) researched cultural and social capital in Aboriginal communities and identified three conditions (i.e., socially invested resources, relationships, and networks) that can have a positive or negative impact on children and adults in First Nations communities. Miyo is also interested in a preliminary exploration of how social capital concepts might strengthen Miyo’s ability to enhance student outcomes.

\section{Methodology}

Members of the research team contacted the Miyo administrators to inquire about their interest in a small-scale research project. During initial discussions, Miyo administrators advised that a primary concern was the low attendance rate of many students, which ultimately leads to poor academic performance and to some students dropping out completely. Acknowledging that it may be difficult to reach those students who do not attend, the researchers and the administrators wondered if something could be learned from those students who attend regularly, and if there might be value in comparing information gained from regular attendees to information from those who attend sporadically and are at risk of not completing their education.

Given that the target population for this research project was comprised of youth from a First Nations school community, it was imperative that an ethics review take place. The ethics application was submitted to the University of Alberta Research Ethics Board in July, 2011, along with: (a) copies of the consent forms for parents and for students of legal age; (b) information sheets for anyone participating or providing consent for someone else to participate in the study; and (c) a copy of the draft survey instrument. There were no requests for revisions and ethics approval was received on August 7, 2011.

\section{Surveys}

The researchers used two surveys for this project:

1. The first was the Developmental Assets Profile (DAP) developed by the Search Institute (2005). Consisting of 58 items, the survey is a standardized method of "eliciting and quantifying information on Developmental Assets” (p. 1) based on responses from the students themselves. The survey was designed to be used for both genders, within an age range of 11 to 18. The DAP was developed with an average reading level at or near Grade 6.

2. Mignone and Lewis' (2005) social capital survey was used to elicit information on student involvement in and knowledge of First Nations culture. The work derived from Mignone's doctoral research completed in Manitoba in collaboration with three First Nations communities and the Health Information and Research Committee of the Assembly of Manitoba Chiefs.

\section{Sample}

Ermineskin Junior/Senior High School students in Grades 10, 11, and 12, as well as students in the Ehpewapahk Community School were invited to complete the surveys. The 
rationale for this age group was twofold. First, as a result of their increased life experience, students in later grades are more likely to have been subjected to opportunities to be involved in unhealthy and/or criminal activity. Second, Ermineskin Junior/Senior High School has approximately 100 students in Grades 10 to 12 and Ehpewapahk School has approximately 45 students, mostly of high school age. The potential number of completed questionnaires was manageable in terms of the project's time frame for compiling and analyzing data.

Prior to the day the surveys were completed, students were invited to submit consent forms. The two schools arranged for students who had submitted consent forms to meet the researchers, and be assured of confidentiality. Students then completed and submitted their surveys directly to the researchers. Miyo provided the researchers with student attendance rates.

\section{Results}

\section{Response rate and respondent characteristics}

Of the 160 high school age students in Miyo, 69 students (43\%) completed a survey. The respondents' average attendance rate (84\%) is somewhat higher than the average attendance rate for the total student population (82\%). Table 1 shows that respondents included a greater proportion of higher-attending students that the total student population.

Table 1. Attendance rate for all high school age students and for survey respondents

$$
n=67^{*}
$$

\begin{tabular}{|c|c|c|c|c|c|c|c|c|c|c|}
\hline \multirow[b]{3}{*}{ Population } & \multicolumn{10}{|c|}{ Attendance Rates } \\
\hline & \multicolumn{2}{|c|}{$\begin{array}{c}90 \% \text { to } \\
100 \%\end{array}$} & \multicolumn{2}{|c|}{$\begin{array}{c}75 \% \text { to } \\
89 \%\end{array}$} & \multicolumn{2}{|c|}{$\begin{array}{c}50 \% \text { to } \\
74 \%\end{array}$} & \multicolumn{2}{|c|}{$\begin{array}{c}\% \text { to } 49 \\
\%\end{array}$} & \multicolumn{2}{|c|}{ Total } \\
\hline & $n$ & $\%$ & $n$ & $\%$ & $n$ & $\%$ & $n$ & $\%$ & $n$ & $\%$ \\
\hline All high school age students & 72 & $46 \%$ & 47 & $30 \%$ & 30 & $19 \%$ & 9 & $6 \%$ & 158 & $100 \%$ \\
\hline Survey respondents & 36 & $54 \%$ & 19 & $28 \%$ & 12 & $18 \%$ & 0 & $0 \%$ & 67 & $100 \%$ \\
\hline
\end{tabular}

*Attendance rate was not available for two new students.

Respondents included a higher proportion of male students (52\%) and a lower proportion of female students (48\%) than the total student population (49\% male and 51\% female). Respondents included a lower proportion of Grade 10 students (58\%), a higher proportion of Grade 11 students (28\%), and an equal proportion (14\%) of Grade 12 students compared to the total high school population (Grade 10: 62\%; Grade 11: 22\%; Grade 12: 14\%). Because the correlation results are so strong, discrepancies between the respondent sample and the total student population do not limit the value of the findings for Miyo (see Table 2). However, the small sample size and these discrepancies suggest the findings may not be generalizable to larger 
youth populations. While the findings are limited to Hobbema and may not be directly generalizable to other Aboriginal communities, many Aboriginal communities share similar characteristics to Hobbema. Thus further research on this topic would be worthwhile and could provide insight into practical interventions that could impact on student school and community involvement in other First Nations communities.

\section{Attendance rate and developmental asset score}

For the purpose of this study, attendance was measured simply by student presence at school. If a student was absent, there was no coding to indicate absenteeism due to illness or some other reason. Miyo assigns the following labels to school attendance: Students who attend more than $90 \%$ of the time are considered to have high attendance rates; those who attend between $75 \%$ and $89 \%$ of the time have moderate attendance rates; and those with less than $75 \%$ attendance rates are considered to have low attendance. In this research sample, students with a history of low school attendance have lower developmental asset scores than students who attend school regularly. As shown in Table 2, the correlation between attendance rate and developmental asset score was very strong.

\section{Table 2. Correlation between Attendance Rate and Average Developmental Asset Score $n=69$}

\begin{tabular}{|c|c|}
\hline Attendance Rate & $\begin{array}{c}\text { Average Developmental Asset Score } \\
\text { (score out of } 60 \text { was converted to a } \\
\text { percentage) }\end{array}$ \\
\hline $90-100 \%$ & 66.86 \\
\hline $75 \%-89 \%$ & 66.23 \\
\hline $50 \%-74 \%$ & 60.92 \\
\hline Correlation & 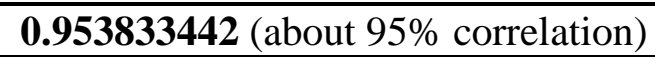 \\
\hline
\end{tabular}

The survey results indicated almost no correlation (.07 in the high school and -.01 in the community school) between attendance rates and students' sense of cultural identity or their perceptions of social capital. Thus, it is not possible to state whether students with a history of low school attendance are likely to have a greater, lesser, or similar sense of cultural heritage, or similar perceptions of positive social capital, compared to students who attend school regularly.

\section{Limitations}

As with any project, care must be taken to understand the findings within the context of the particular study. This study had a small sample size and was undertaken in a First Nations school. The findings are relevant for Miyo school authorities but one cannot assume that the findings would be equally relevant in a non-Aboriginal community, in another First Nations community, or in another First Nations school. 
International Journal of Child, Youth and Family Studies (2013) 1: 42-53

The pen and paper nature of the survey itself is a further limitation. The survey had a Grade 6 reading level, and researchers read the questions out loud to some students to increase their opportunity to understand. Still, about five students visibly struggled with the task. Their surveys could not be used because of incomplete answers, or answers with a pattern that suggested these students did not read or understand the questions.

Finally, in order to complete a survey, one had to be present at school. Thus, those students who completed a survey are perhaps from the group who place an importance on regular attendance. Our data shows that of those students whose attendance rates are less than 50\%, none completed a survey. A further line of inquiry, then, might be with the population that attends less than $50 \%$ of the school year.

\section{Discussion}

The results reported above do not tell the entire story. As is often the case, the smaller details provide the nuances and point to areas worthy of more analysis and follow-up action. Research from The Search Institute has repeatedly shown that the more developmental assets a child has, the more likely he or she will avoid risk-taking behaviour, make healthy choices, and succeed in a variety of arenas, including school (Starkman, Scales, \& Roberts, 2006, p. 14). Our data revealed a strong correlation between regular school attendance and a higher developmental assets score. This finding is consistent with previous research.

The immediate teaching, learning, and follow-up opportunities from this research are for Miyo school authorities. The challenge and the opportunity for Miyo derive from some of the other connections that were revealed in the data analysis.

Throughout the survey, students validated the work their teachers are doing. Students at both schools perceive their teachers to be encouraging ( $90 \%$ of the maximum score). Students also had high average scores for "I have a caring school" (87\%), "My school has clear rules" (80\%), and "I am engaged in learning" (80\%). Students at the community school rated the school as their highest source of support (93\% of the maximum possible score) while students at the high school rated "caring school” and "family support” as equally strong sources of support (both school and family received 83\% of the maximum score). Miyo school authorities can be assured that their work efforts and concerns are noted and are making a difference in the school experience of their students. These are strengths on which to build. These results suggest that the school may be one means through which student commitment to school, community, and culture can be encouraged. For example, perhaps the school could work to include parents and other members of the community to engage students in activities that facilitate cultural knowledge and experience. It may be that the school in this community has the potential to provide linkages to family, social, and cultural factors that can strengthen bonds and build developmental assets. If students respect and "connect" with school, then expanding the role of the school in the community might be one avenue for building on developmental assets among young people in this community.

Students with higher developmental assets also reflected a significant degree of support from parents and family. For example, students at the high school rated "parents' help” as their highest source of support (87\% of the maximum possible score) and students at both schools 
International Journal of Child, Youth and Family Studies (2013) 1: 42-53

rated "parents' encouragement" at $87 \%$ of maximum score. Most students also feel safe at home ( $80 \%$ of the maximum score). There is an opportunity for Miyo to work even more closely with students' families in support of building developmental assets.

On the other hand, not every student has supportive family circumstances. A total of $9 \%$ of respondents had family context scores that the Search Institute considers “ low” (less than $50 \%$ of the maximum score) and another $11 \%$ had scores for family context that the Search Institute considers only "fair" (less than 65\% of the maximum score). For these students, school may be their strongest - and perhaps only - positive supportive environment.

Respondents' average scores related to community context (developmental assets questions) were 56\% of the maximum score, which the Search Institute considers "fair". Respondents' average scores related to community and cultural strengths (social capital questions) were $53 \%$ of the maximum score. In the developmental assets questions, $70 \%$ of respondents had community context scores that were "fair" or "low". In the social capital questions, 77\% of respondents had "social capital” scores that were "fair” or "low”.

From these scores, it appears that respondents do not perceive their community to be a source of positive cultural or social support. However, a growing body of work states that Aboriginal youth do better when they have a positive sense of their cultural identity and their community (see, for example, Tousignant \& Sioui, 2009; Mignone \& O’Neil, 2005; Williams \& Mumtaz, 2007). Since this study indicates that more than two-thirds of Miyo students do not perceive their community as supportive, Miyo may find it beneficial to work with others in the community to help strengthen the components that make the community a supportive environment for youth, whether or not a supportive environment is correlated to high attendance.

Student social capital scores suggest that the few areas of strength on which to build a stronger community context include: "proud to be my First Nation” (83\% of the maximum score), number of community events attended (76\% of the maximum score), "traditional activities" (70\% of the maximum score), and "friends in other First Nations" (70\% of the maximum score).

There are a number of specific practical and policy implications that arise as a result of the findings of this study:

For Miyo Wahkohtowin Community Education Authority. Miyo schools are already positioned as an epicentre of activity within the larger community. Enhancing this strength will have positive benefits for students and the community. There are two reasons for this. The first was cited in a literature review completed by the Alaska School Boards' Initiative for Community Engagement (Boettcher, 2004). Extensive review of research pertaining to Aboriginal students and schools noted that: "Native students are more likely to do better in school when they feel connected to their parents, communities and teachers” (p. 8).

The second reason for positioning the schools as the centre of activity for Ermineskin members is that schools, particularly in small communities, can and often do play a much larger role in the lives of students and their families. In Great Places to Learn: How asset-building schools help students succeed (Starkman, Scales, Roberts, \& Blegen, 1999), the Search Institute 
International Journal of Child, Youth and Family Studies (2013) 1: 42-53

identifies 13 out of 40 assets that schools can directly influence. The 13 assets include parent involvement in schooling, other adult relationships, peer influence, interpersonal competence, high expectations, caring school climate, school boundaries, school engagement, academic motivation, homework, reading for pleasure, and youth programs. A number of these assets have points of contact with the broader community, with parents, or with family life.

In deciding where to prioritize, it may be optimal to select those areas that are easiest to influence, most likely to be supported, achievable within available resources, and likely to demonstrate measurable positive results most quickly. Identifying specific priorities is beyond the scope of this project. More detailed information about survey results has been provided to Miyo, and this information may suggest areas of greatest strength on which to build.

For crime prevention programs and Aboriginal youth programs. Programming that increases the number and strength of developmental assets for youth can easily be incorporated into existing programs. Organizations such as Thrive Canada ${ }^{1}$ or the Search Institute of Minneapolis ${ }^{2}$ have a myriad of resources to assist with asset building. Most of the ideas require little in the way of financial resources, making them very attractive to agencies with limited budgets.

For researchers and practitioners working in crime prevention, health promotion, or community development. Again, the Search Institute and Thrive Canada both have a wealth of information related to asset building. Given the emphasis on community within asset building, it is also recommended that consideration be given to the emerging literature on social capital. These two streams of thinking have the potential to be significant factors in the development of healthy youth and vibrant communities.

\section{Conclusion}

The link between poor academic performance and delinquency is well established in the academic literature. Academic performance, in turn, is affected by attendance. Curious about the link between First Nations students' engagement in their education, as measured by attendance rates, and students' engagement with culture and community, Miyo Wahkohtowin Community Education Authority of Ermineskin First Nation in Hobbema ("Miyo") partnered with the researchers to explore the possible linkages between school attendance and developmental assents among high school age students. A second objective of the current study was to explore the potential relationship between school attendance and sense of cultural heritage and perceptions of positive social capital in their community. Results from a survey administered to high school age students indicate that, at least for this sample, students with a history of low school attendance have lower developmental asset scores than students who attend school regularly. In terms of the second research objective, survey results indicate almost no correlation between attendance rate and students' sense of cultural identity or their perceptions of social capital. In light of the fact that more than two-thirds of Miyo students do not perceive their community as supportive, Miyo may find it beneficial to work with others in the community to

\footnotetext{
${ }^{1}$ Thrive Canada is now Lions Quest Canada www.lionsquest.ca/

${ }^{2}$ www.search-institute.org/
} 
International Journal of Child, Youth and Family Studies (2013) 1: 42-53

help strengthen the components that make the community a supportive environment for youth, whether or not a supportive environment is correlated to high attendance.

This exploratory study has relevance for other First Nation school authorities, as well as criminologists, program designers, or practitioners in crime prevention, child and youth development, mental health promotion, and community development. The study results suggest that activities to strengthen developmental assets among Aboriginal youth correlates with higher school attendance, which in turn may enhance positive social outcomes and reduce the risk of harmful behaviour. As well, learning more about strengthening the positive components of social capital in Aboriginal communities may be a productive line of research. 
International Journal of Child, Youth and Family Studies (2013) 1: 42-53

\section{References}

Boettcher, K. (2004). Asset building and student achievement. A literature review and bibliography of research and resources. Juneau: Alaska Initiative for Community Engagement.

Brzozowski, J.-A., Taylor-Butts, A., \& Johnson, S. (2006). Victimization and offending among the Aboriginal population in Canada. Catalogue no. 85-002-XIE, 26(3). Ottawa: Statistics Canada.

Government of Alberta. (2010). The Northland School Division Inquiry team report. Edmonton: Author.

Grekul, J., \& LeBoucane-Benson, P. (2008). Aboriginal gangs and their (dis)placement: Contextualizing recruitment, membership and status. Canadian Journal of Criminology and Criminal Justice, 50, 31-57.

Grekul, J., \& Sanderson, K. (2011). “I thought people would be mean and shout”. Introducing the Hobbema community cadet corps: A response to youth gang involvement? Journal of Youth Studies, 13(6), 1-17.

Maguin, E., \& Loeber, R. (1996). Academic performance and delinquency. In M. Tonry (Ed.), Crime and justice: A review of research (Vol. 20, pp. 145-264). Chicago: University of Chicago Press.

Mercredi, O. W. (2000). Aboriginal gangs: A report to the Correctional Service of Canada on Aboriginal youth gang members in the federal corrections system. Ottawa: Correctional Service Canada.

Mignone, J., \& O’Neil, J. (2005). Conceptual understanding of social capital in First Nations communities: An illustrative concept. Pimatisiwin: A Journal of Aboriginal and Indigenous Community Health, 3(2), 8-44.

Search Institute. (2005). Developmental Assets Profile, group assessment user manual. Minneapolis, MN: Author.

Solomon, P. (1992). Black resistance in high school: Forging a separatist culture. Albany, NY: State University of New York Press.

Starkman, N., Scales, P., Roberts, C., \& Blegen, M. B. (1999). Great places to learn: How assetbuilding schools help students succeed. Minneapolis, MN: Search Institute. 
International Journal of Child, Youth and Family Studies (2013) 1: 42-53

Starkman, N., Scales, P., \& Roberts, C. (2006). Great places to learn: Creating asset-building schools that help students succeed (2nd ed.). Minneapolis, MN: Search Institute.

Tousignant, M., \& Sioui, N. (2009). Resilience and Aboriginal communities in crisis: Theory and interventions. Journal of Aboriginal Health, 5, 43-61. Ottawa: National Aboriginal Health Organization (NAHO)

Trocme, N., Knoke, D., \& Blackstock, C. (2004). Pathways to overrepresentation of Aboriginal children in Canada’s child welfare system. Social Service Review, 78(4), 577-600.

Williams, L., \& Mumtaz, Z. (2007, February). Being alive well. Aboriginal youth and evidencebased approaches to promoting mental well-being. Prepared by the Prairie Region Health Promotion Research Centre for the National Aboriginal Youth Mental Health Promotion Strategy (NAYSPS) Symposium hosted by the First Nations and Inuit Health Branch, Saskatoon, SK. 